\title{
Effects of calcination temperature on the catalyst performance in a $\mathrm{CO} 2$ hydrogenation reaction
}

\author{
Nur Insyirah Zulkifli ${ }^{a}$, Noor Asmawati Mohd Zabidi ${ }^{\mathrm{b}}$, Sara Faiz Tasfy \\ a,b Institute of Contaminant Management, Center of Contaminant Control and Utilization (CenCoU) Universiti Teknologi \\ PETRONAS, Seri Iskandar, Perak, Malaysia \\ ${ }^{c}$ American University of Ras Al Khaimah, Ras Al Khaimah, UAE \\ Email:ainsyirahzulkiflii@gmail.com, ${ }^{b}$ noorasmawati_mzabidi@utp.edu.my, ${ }^{c}$ sara.tasfy@aurak.ac.ae
}

Article History: Received: 10 November 2020; Revised 12 January 2021 Accepted: 27 January 2021; Published online: 5 April 2021

\begin{abstract}
Cu} / \mathrm{ZnO}$ catalysts were synthesized on $\mathrm{Al} 2 \mathrm{O} 3-\mathrm{ZrO} 2$ support via impregnation method with addition of manganese and niobium promoters. Samples were calcined at 181,350 and $518{ }^{\circ} \mathrm{C}$. Different characterization techniques such as H2-TPR and CO2-TPD were used to study the catalytic reduction behavior and catalytic basicity, respectively. H2-TPR studies shows that all the catalysts reduction occurred on the range of temperature between $237^{\circ} \mathrm{C}$ and $265^{\circ} \mathrm{C}$. The $\mathrm{CO} 2-\mathrm{TPD}$ profiles showed that the calcination temperature significantly influences the basicity of the catalyst and the catalyst calcined at $350 \mathrm{oC}$ was proved to contain the highest amount of the basic sites. Furthermore, the characterization results were validated through analyzing of the catalyst performance during $\mathrm{CO} 2$ hydrogenation reaction and the results indicate that highest methanol yield of $12.2 \%$ were obtained from the catalyst that calcined $350 \mathrm{oC}$.
\end{abstract}

Keywords: Methanol, CO2 Hydrogenation, calcination temperature

\section{Introduction}

Methanol, also known as wood alcohol was commercially obtained from destructive distillation of wood before mainly produced by hydrogenation of carbon monoxide (Equation 1). At room temperature, methanol exists as a polar colorless, volatile, and flammable liquid form. Methanol, being the simplest type of alcohol, has a distinctive odor similar to the drinking alcohol, ethanol but far more toxic than ethanol [1]. Despite that, methanol has been identified as a precursor to other commodity chemicals such as acetic acid, dimethyl ether, and methane, hence, more than 20 million tons of methanol is being produced annually for these industrial demands[2]-[4].

$$
\begin{aligned}
& \mathrm{CO}+2 \mathrm{H}_{2} \rightarrow \mathrm{CH}_{3} \mathrm{OH} \\
& \mathrm{CO}_{2}+2 \mathrm{H}_{2} \rightarrow \mathrm{CH}_{3} \mathrm{OH}+2 \mathrm{H}_{2} \mathrm{O}
\end{aligned}
$$

In this era, the significant increase of $\mathrm{CO}_{2}$ content in the earth's atmosphere develops researchers' interests to produce valuable chemicals from $\mathrm{CO}_{2}$, such as methanol, as shown in equation 2 [5]-[7]. This process is one of the best options for storing energy in a most convenient form of liquid fuels with sufficiently high energy density in comparison to all the existing methods of energy storage [8]. However, this process is also very challenging due to the high stability of the $\mathrm{CO}_{2}$.

Commercially, methanol is synthesized from syngas feedstock using $\mathrm{Cu} / \mathrm{ZnO} / \mathrm{Al}_{2} \mathrm{O}_{3}$ catalyst [9]. Besides the commercialized alumina support, zirconia $\left(\mathrm{ZrO}_{2}\right)$ is utilized as one of main catalyst components because of its strength and thermal-resistant property. Findings by Witoon et al. suggests that $\mathrm{CO}_{2}$ hydrogenation is highly influenced by the zirconia phase, $\mathrm{Cu}-\mathrm{ZrO}$ interaction of amorphous $-\mathrm{ZrO}_{2}$ and tetragonal- $\mathrm{ZrO}_{2}$ is stronger than monoclinic- $\mathrm{ZrO}_{2}$ [10]. A study conducted by Zhang et al. proved that the presence of $\mathrm{ZrO}_{2}$ in the commercial $\mathrm{CO}_{2}$ hydrogenation catalyst has increased the $\mathrm{CO}_{2}$ conversion up to $25.9-24.7 \%$ at $250{ }^{\circ} \mathrm{C}$ and $5 \mathrm{MPa}$ using $10 \%$ of alumina sol in a slurry bed reactor [11]. Recently, $\mathrm{ZrO}_{2}$ also found to reduce weak basic sites which resulted in high methanol selectivity $(75 \%)$ over the $\mathrm{CuO}-\mathrm{ZnO}$ catalyst which was calcined at temperature $>600{ }^{\circ} \mathrm{C}[12]$.

Besides $\mathrm{ZrO}_{2}$, manganese (Mn), zirconium $(\mathrm{Zr})$, titanium ( $\left.\mathrm{Ti}\right)$, lead $(\mathrm{Pb})$, etc. also exhibit ability to fine-tune interfaces between their oxides and active copper which promote methanol selectivity and the stability of the catalyst[13]-[17]. For instance, $\mathrm{TiO}_{2}, \mathrm{ZrO}_{2}$, and $\mathrm{TiO}_{2}-\mathrm{ZrO}_{2}$ mixed-oxide on $\mathrm{CuO}-\mathrm{ZnO}$ catalyst have been reported to improve the $\mathrm{CuO}$ dispersion and increase the $\mathrm{Cu}$ surface area and adsorption capacities of $\mathrm{CO}_{2}$ and $\mathrm{H}_{2}$ [18] - [19]

This study investigated the roles of calcination temperatures on physiochemical properties of $\mathrm{Mn}$ and $\mathrm{Nb}$ - 
promoted $\mathrm{Cu} / \mathrm{ZnO} / \mathrm{Al}_{2} \mathrm{O}_{3}-\mathrm{ZrO}_{2}$ catalyst and their performance in $\mathrm{CO}_{2}$ hydrogenation reaction into methanol. The synthesized catalysts were characterized with field emission scanning electron microscope (FESEM), hydrogen temperature-programmed reduction, $\mathrm{H}_{2}-\mathrm{TPR}$, and carbon dioxide temperature-programmed desorption $\left(\mathrm{CO} \mathrm{O}_{2}-\mathrm{TPD}\right)$ techniques.

\section{2.methodology (experimental)}

\subsection{Catalyst Synthesis}

The catalyst was prepared using an impregnation method with $15 \mathrm{wt} \%$ metal loading at $\mathrm{Cu}$ to $\mathrm{ZnO}$ ratio of 7:3. A total of $0.09 \%$ of $\mathrm{Mn}$ and $\mathrm{Nb}$ metals were incorporated into the catalyst as promoters. For synthesis of $10 \mathrm{~g}$ catalyst, $0.021 \mathrm{~g}$ of $\mathrm{Mn}\left(\mathrm{NO}_{3}\right)_{2} .4 \mathrm{H}_{2} \mathrm{O}$ [Merck], 0.014g of $\mathrm{C}_{4} \mathrm{H}_{4} \mathrm{NNbO}_{9}$ [Merck], 3.995g of $\mathrm{Cu}\left(\mathrm{NO}_{3}\right)_{2}[\mathrm{Merck}$, and $1.644 \mathrm{~g}$ of $\mathrm{Zn}\left(\mathrm{NO}_{3}\right)_{2}$ [Sigma Aldrich], were dissolved in deionized water and stirred for 1 hour and then added dropwise onto the $\mathrm{Al}_{2} \mathrm{O}_{3}-\mathrm{ZrO}_{2}$ [SASOL] powder. The mixture was continuously stirred for 24 hours and the pH was maintained at 7 using $10 \%$ ammonia solution, $\mathrm{NH}_{4} \mathrm{OH}$ [Merck]. Then the mixture was filtered and the sample was washed using deionized water. The sample was dried at $120^{\circ} \mathrm{C}$ for 12 hours and then calcined statically at the presence of air for 4 hours under different range of temperature 181,350 and $518{ }^{\circ} \mathrm{C}$ to study the effect of the calcination temperature on the catalytic performance.

\subsection{Catalyst Evaluation}

Catalyst evaluation was performed in a fixed-bed reactor (Microactivity Reference, PID Eng Tech). Prior to the reaction, a $0.2 \mathrm{~g}$ of sample was treated in 5 vol\% of $\mathrm{H}_{2}$ in Argon gas at $20 \mathrm{~mL}$ min- ${ }^{1}$ for 2 hours. The $\mathrm{CO}_{2}$ hydrogenation reaction was performed at $22.5 \mathrm{bar}, 250^{\circ} \mathrm{C}$, and $1: 3$ of $\mathrm{CO}_{2}: \mathrm{H}_{2}$ with a total flow rate of $36 \mathrm{~mL} / \mathrm{min}$ for 5 hours. The reactor effluents were analyzed using a gas chromatograph (Agilent 7890A) equipped with a TCD detector for $\mathrm{H}_{2}$ and $\mathrm{CO}_{2}$ analysis, and FID detector for analysis of alcohols and other hydrocarbons [20]. $\mathrm{CO}_{2}$ conversion, alcohol selectivity and methanol yield were calculated using Equation 1, equation 2, and equation 3, respectively.

$$
\begin{aligned}
& \mathrm{CO}_{2} \text { conversion }(\%)=\frac{\text { Mole of } \mathrm{CO}_{2} \text { in }- \text { Mole of } \mathrm{CO}_{2} \text { out }}{\text { Mole of } \mathrm{CO}_{2} \text { in }} \times 100 \\
& \text { Methanol selectivity }(\%)=\frac{\text { mole of methanol produced }}{\text { total mole of product }} \times 100 \\
& \text { (2) Methanol yield }(\%)=\frac{\mathrm{CO}_{2} \text { conversion }(\%)}{100} \times \text { Methanol selectivity }(\%)
\end{aligned}
$$

\subsection{Catalyst Characterization}

The morphology was observed on a Hitachi-8020 field emission scanning electron microscope (FESEM) at 5K magnification. The reduction profile of the catalyst was studied via the hydrogen temperature-programmed reduction $\left(\mathrm{H}_{2}\right.$-TPR) using a TPR equipment (1100 CE Instrument). 40-50 mg catalyst was placed in the quartz tube and was pre-treated at $250^{\circ} \mathrm{C}$ with a ramping rate of $10^{\circ} \mathrm{C} / \mathrm{min}$ under the flow of pure $\mathrm{N}_{2}$ for 1 hour. The analysis was then continued by flowing $5 \% \mathrm{H}_{2} / \mathrm{Ar}(20 \mathrm{~mL} / \mathrm{min})$ and heated to $990^{\circ} \mathrm{C}$ at $10^{\circ} \mathrm{C} / \mathrm{min}$ for an hour. The carbon dioxide temperature-programmed desorption experiments $\left(\mathrm{CO}_{2}\right.$-TPD) were conducted using the same instrument as $\mathrm{H}_{2}$-TPR experiments. The $\mathrm{CO}_{2}$-TPD experiments were carried out by placing 40-50 mg of the calcined catalyst in the quartz tube and was pre-treated at $250^{\circ} \mathrm{C}$ with a ramping rate of $10^{\circ} \mathrm{C} / \mathrm{min}$ under He flow $\left(20 \mathrm{~mL} / \mathrm{min}\right.$ ) for an hour. The $\mathrm{CO}_{2}$ sorption then continued by continuous $\mathrm{CO}_{2}$ flow at $10 \mathrm{~mL} / \mathrm{min}$ for 30 minutes at $75^{\circ} \mathrm{C}$.

\section{Results And Discussion}

\subsection{Morphological Properties Of The Catalyst}

FESEM images for catalyst samples calcined at different temperatures are shown in Fig. 1. All catalyst samples exhibit irregular morphology. Increasing the calcination temperature from 181 to $518{ }^{\circ} \mathrm{C}$ did not change the morphology of the samples. 

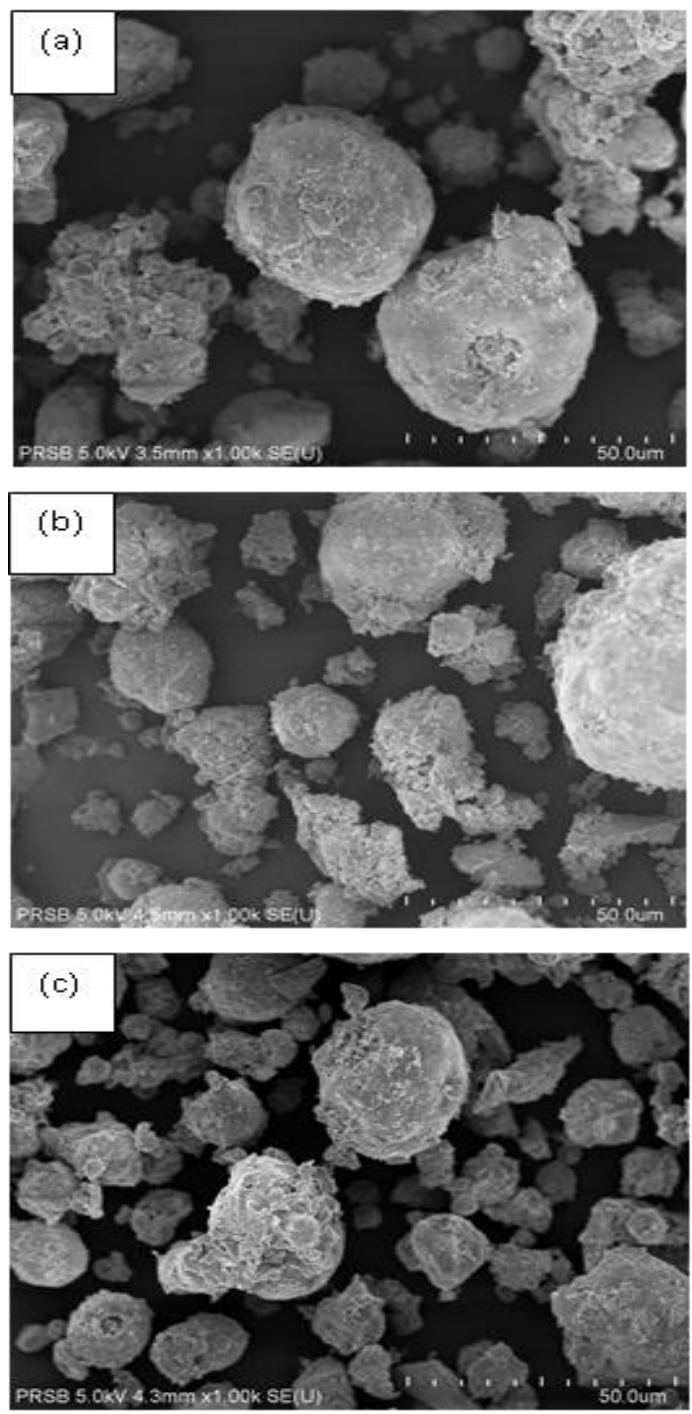

Fig. 1. FESEM images of catalysts calcined at (a) $181{ }^{\circ} \mathrm{C}$ (b) $350{ }^{\circ} \mathrm{C}$, and (c) $518{ }^{\circ} \mathrm{C}$

Fig. 2 shows the $\mathrm{H}_{2}$-TPR profiles for catalyst samples calcined at 181,350 and $518{ }^{\circ} \mathrm{C}$. The amount of hydrogen consumed and the corresponding reduction temperature are shown in Table 1. Samples calcined at 181 and $350{ }^{\circ} \mathrm{C}$ exhibit two distinct TPR peaks, denoted as $\alpha$ and $\beta$, due to the stepwise reduction behavior of the $\mathrm{Cu}$ based catalysts. The $\alpha$ peak resulted from the reduction of highly dispersed copper oxide species which are easier to reduce while the $\beta$ peak is ascribed to the reduction of bulk-like $\mathrm{CuO}$ [7], [21]. The occurrence of reduction with shoulder peaks had also been reported previously in the literature[22]. The $\mathrm{H}_{2}$-TPR profiles show that reduction for the catalysts occurred between $235^{\circ} \mathrm{C}$ to $265^{\circ} \mathrm{C}$. For the sample calcined at $518^{\circ} \mathrm{C}$, only a single $\mathrm{H}_{2^{-}}$ TPR peak was observed at $237{ }^{\circ} \mathrm{C}$, which suggest that at high calcination temperature the bulk-like $\mathrm{CuO}$ was reduced directly to $\mathrm{Cu}^{0}$ instead of the stepwise reduction process which also consumed the least amount of hydrogen $(1123 \mu \mathrm{mol} / \mathrm{g})$. 


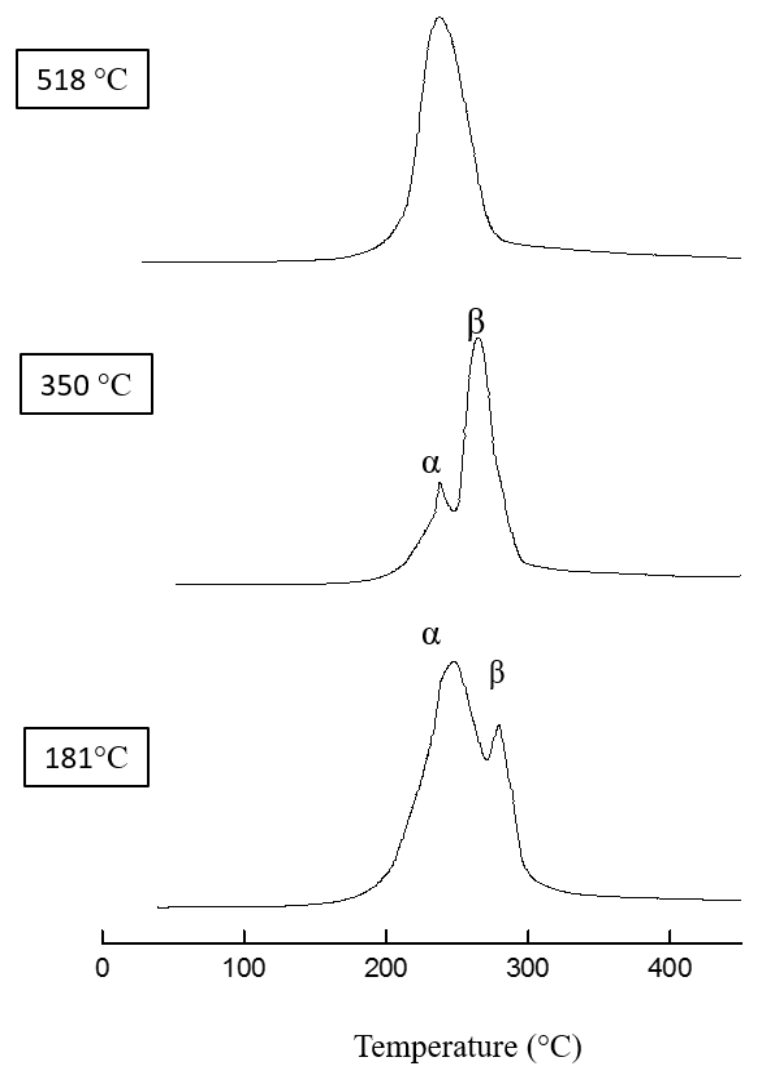

Fig. 2. $\mathrm{H}_{2}$-TPR profiles of the catalysts

Table 1. $\mathrm{H}_{2}$-TPR data of catalysts

\begin{tabular}{|c|c|c|c|c|c|}
\hline \multirow[t]{2}{*}{$\begin{array}{l}\text { Calcination } \\
\text { temperature } \\
\left({ }^{\circ} \mathrm{C}\right)\end{array}$} & \multirow[t]{2}{*}{$\begin{array}{l}\quad \mathrm{H}_{2} \\
\text { consumption } \\
(\mu \mathrm{mol} / \mathrm{g}) \\
\text { peak }\end{array}$} & \multicolumn{2}{|c|}{$\begin{array}{l}\quad \text { Reducti } \\
\text { on } \\
\text { temperature } \\
\left({ }^{\circ} \mathrm{C}\right)\end{array}$} & \multicolumn{2}{|c|}{$\begin{array}{l}\quad \mathrm{H}_{2} \\
\text { consumption } \\
(\mu \mathrm{mol} / \mathrm{g}) \\
\text { peak }\end{array}$} \\
\hline & & $\alpha$ & $\beta$ & $\alpha$ & $\beta$ \\
\hline 181 & 1403 & $38^{2}$ & $65^{2}$ & $22^{3}$ & $\begin{array}{r}1 \\
081\end{array}$ \\
\hline 350 & 2875 & $48^{2}$ & $60^{2}$ & $\begin{array}{r}1 \\
881\end{array}$ & $94^{9}$ \\
\hline 518 & 1123 & \multicolumn{2}{|c|}{237} & \multicolumn{2}{|c|}{1123} \\
\hline
\end{tabular}

Fig. 3. shows the $\mathrm{CO}_{2}$-TPD profiles of the catalysts and the data are shown in Table 2. The TPD peak at temperature $<200^{\circ} \mathrm{C}$ is related to the weak basic sites which were contributed by the weakly-held surface hydroxyl groups $(-\mathrm{OH})$. The medium basic sites $\left(200^{\circ} \mathrm{C}-500^{\circ} \mathrm{C}\right)$ were attributed to metal oxygen pairs i.e. $\mathrm{Cu}-\mathrm{O} \mathrm{Al}-\mathrm{O}, \mathrm{Zn}-$ $\mathrm{O}, \mathrm{Mn}-\mathrm{O}, \mathrm{Nb}-\mathrm{O}$ and $\mathrm{Zr}-\mathrm{O}$ [23] - [24]. The high temperature desorption peaks (above 500 ${ }^{\circ} \mathrm{C}$ ) represent the strong basic sites that are associated with coordinatively unsaturated $\mathrm{O}_{2}-$ ions (low coordination oxygen atoms) from partial breakup of metal-oxygen pairs [25]. The sample that was calcined at the lowest temperature $\left(181{ }^{\circ} \mathrm{C}\right)$ contained mostly medium basic sites $(\beta)$. However, the sample that was calcined at $350{ }^{\circ} \mathrm{C}$ exhibited weak, medium and strong basic sites and had the highest amount of basic sites $(574 \mu \mathrm{mol} / \mathrm{g})$. Nevertheless, the mediumstrength basic sites disappeared when the calcination temperature was increased to $518{ }^{\circ} \mathrm{C}$ and the total amount of basic sites also decreased significantly to $88 \mu \mathrm{mol} / \mathrm{g}$. 
Table 2. $\mathrm{CO}_{2}$-TPD data for the catalysts

\begin{tabular}{|c|c|c|c|c|c|c|c|}
\hline \multirow[t]{2}{*}{$\begin{array}{l}\text { Calcination } \\
\text { temperature } \\
\left({ }^{\circ} \mathrm{C}\right)\end{array}$} & \multirow{2}{*}{$\begin{array}{l}\text { Total } \\
\text { basic } \\
\text { sites } \\
(\mu \mathrm{mol} / \mathrm{g})\end{array}$} & \multicolumn{3}{|c|}{$\begin{array}{l}\text { Peak } \\
\text { Temperature } \\
\left({ }^{\circ} \mathrm{C}\right)\end{array}$} & \multicolumn{3}{|c|}{$\begin{array}{l}\mathrm{CO}_{2} \\
\text { consumption } \\
(\mu \mathrm{mol} / \mathrm{g}) \text { peak }\end{array}$} \\
\hline & & $\mathrm{T}_{1}$ & $\mathrm{~T}_{2}$ & $\mathrm{~T}_{3}$ & $\alpha$ & $\beta$ & $\gamma$ \\
\hline 181 & 268 & - & 451 & 825 & - & 209 & 59 \\
\hline 350 & 574 & 152 & 440 & 870 & 75 & 392 & 107 \\
\hline 518 & 88 & 154 & - & 899 & 26 & - & 62 \\
\hline
\end{tabular}

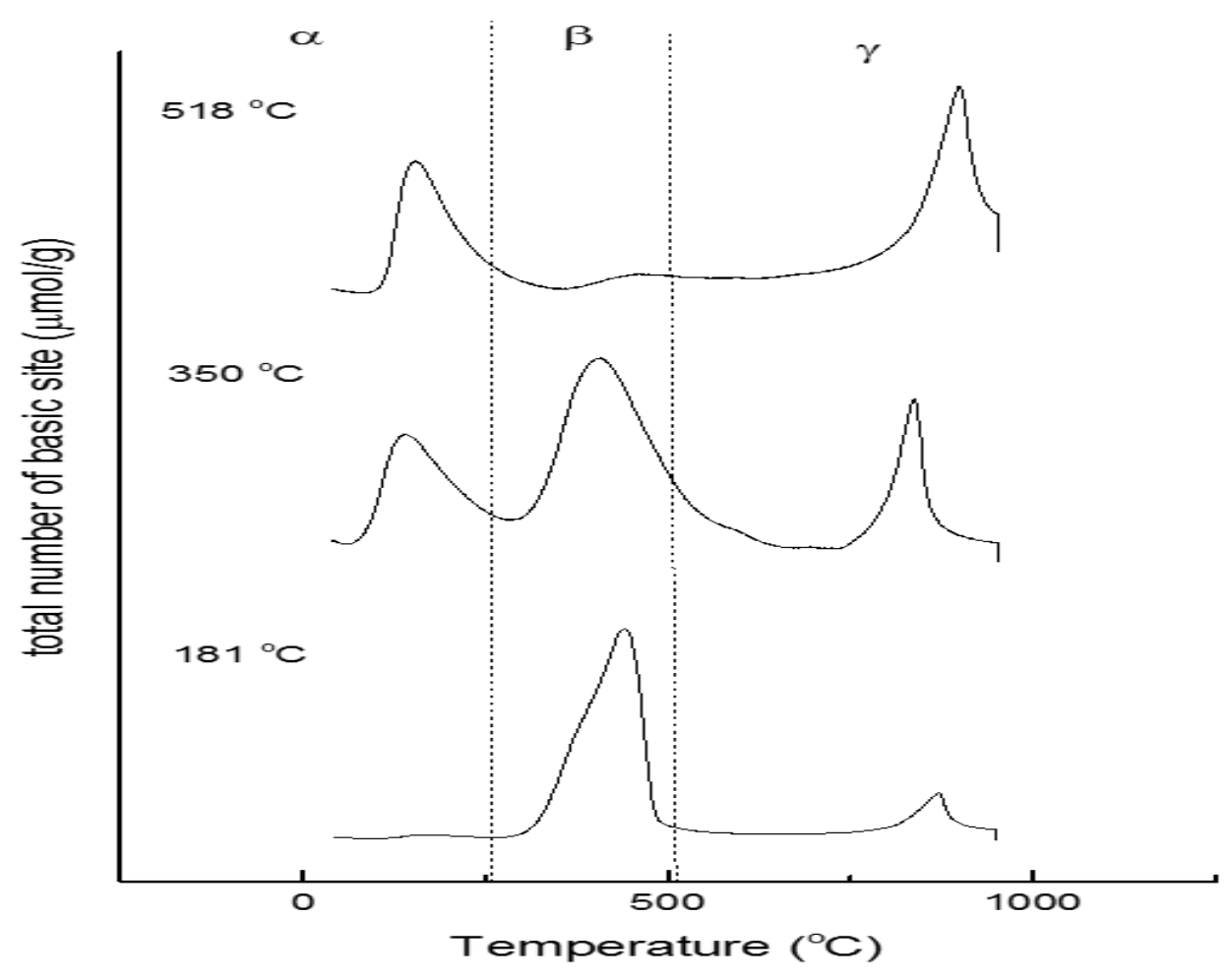

Fig. 3. $\mathrm{CO}_{2}$-TPD profiles of the catalysts

Table 3 shows the catalystic activity in a $\mathrm{CO}_{2}$ hydrogenation reaction performed at reaction temperature of 250 ${ }^{\circ} \mathrm{C}$ and reaction pressure of 22.5 bar. The values of $\mathrm{CO}_{2}$ conversion ranged from 6.5 to $16 \%$ while the methanol selectivity varied from 19.5 and $75.9 \%$ using catalysts that were calcined at various temperatures. The highest methanol yield $(12.2 \%)$ was achieved using a catalyst that was calcined at $350{ }^{\circ} \mathrm{C}$. The catalytic activity is proved to be affected by the presence and the amount of the basic sites. Compared to the other catalysts, the sample that was calcined at $350{ }^{\circ} \mathrm{C}$ contained the highest amount of basic sites $(574 \mathrm{umol} / \mathrm{g}$ ) comprising weak, medium and strong basic sites which resulted in the highest catalytic activity. The sample that was calcined at high temperature $\left(518{ }^{\circ} \mathrm{C}\right)$ might have been sintered and did not possess enough active sites to activate the $\mathrm{CO}_{2}$ molecules, thus resulting in low $\mathrm{CO}_{2}$ conversion. Our findings are in agreement with those of Shaharun et al. as they reported rapid catalyst weight loss starting below $200^{\circ} \mathrm{C}$ and continued up to $350^{\circ} \mathrm{C}$ for $\mathrm{Cu} / \mathrm{ZnO} / \mathrm{Al}_{2} \mathrm{O}_{3} / \mathrm{ZrO}_{2}$ catalyst [26]. Fig. 4 shows effects of catalysts' calcination temperature on the yields of methanol in a $\mathrm{CO}_{2}$ hydrogenation reaction. Based on this trend, $350{ }^{\circ} \mathrm{C}$ was found to the suitable catalyst calcination temperature that results in higher conversion, selectivity and methanol yield.

Table 3. Catalysts performance in a $\mathrm{CO}_{2}$ hydrogenation reaction at $22.5 \mathrm{bar}, 250{ }^{\circ} \mathrm{C}$ for 5 hours.

\begin{tabular}{|l|l|l|l|l|}
\hline Run & $\begin{array}{l}\text { Calcination } \\
\text { temperature } \\
\left({ }^{\circ} \mathrm{C}\right)\end{array}$ & $\begin{array}{l}\mathrm{CO}_{2} \\
\text { conversion } \\
(\%)\end{array}$ & $\begin{array}{l}\text { Methanol } \\
\text { selectivity } \\
(\%)\end{array}$ & $\begin{array}{l}\text { Methanol } \\
\text { yield } \\
(\%)\end{array}$ \\
\hline 1 & 181 & 6.5 & 19.5 & 1.3 \\
\hline 2 & 350 & 16.0 & 75.9 & 12.2 \\
\hline 3 & 518 & 7.2 & 58.4 & 4.2 \\
\hline
\end{tabular}




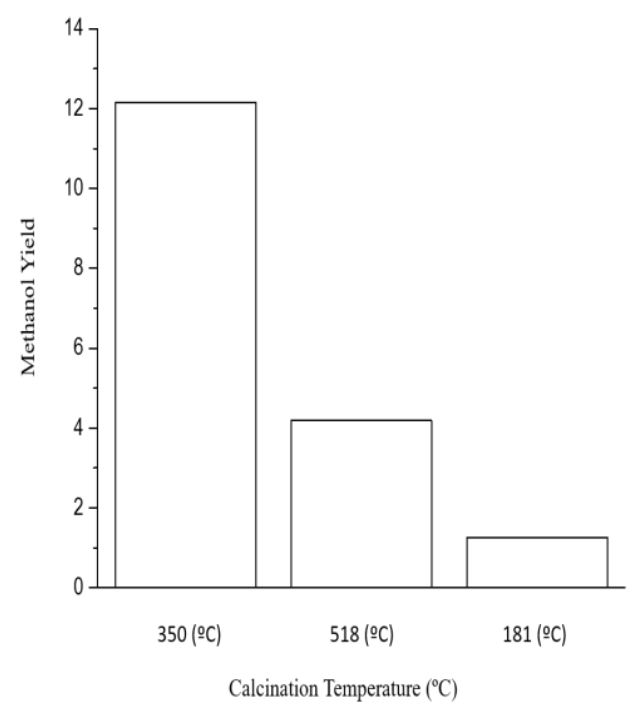

Fig. 4. Effect of catalysts' calcination temperature on methanol yields.

\section{Conclusion}

Effects of calcination temperature for $\mathrm{Mn} / \mathrm{Nb}$-promoted $\mathrm{Cu} / \mathrm{ZnO} / \mathrm{Al}_{2} \mathrm{O}_{3}-\mathrm{ZrO}_{2}$ catalyst have been investigated. All the catalyst exhibits irregular shape and reduced below $300{ }^{\circ} \mathrm{C}$. The catalyst that was calcined at $350{ }^{\circ} \mathrm{C}$ exhibited the highest amounts of basic sites $(574 \mathrm{umol} / \mathrm{g})$ and resulted in the highest $\mathrm{CO}_{2}$ conversion $(16.0 \%)$, methanol selectivity (75.9\%) and methanol yield (12.2\%).

\section{Acknowledgement}

The authors would like to acknowledge the financial support from International Collaborative Research Fund (Cost center: 015ME0-207) and Universiti Teknologi PETRONAS (UTP).

\section{References}

E. Fiedler, G. Grossmann, D. B. Kersebohm, C. Witte, C. Deactivation, and O. C. Systems, "Methanol 1," 2005.

A. Vita, C. Italiano, L. Pino, M. Laganà, M. Ferraro, and V. Antonucci, "High-temperature CO2 methanation over structured Ni/GDC catalysts: Performance and scale-up for Power-to-Gas application," Fuel Process. Technol., vol. 202, pp. 106365, 2020.

P. S. Sai Prasad, J. W. Bae, S. H. Kang, Y. J. Lee, and K. W. Jun, "Single-step synthesis of DME from syngas on $\mathrm{Cu}-\mathrm{ZnO}-\mathrm{Al} 2 \mathrm{O} 3 /$ zeolite bifunctional catalysts: The superiority of ferrierite over the other zeolites," Fuel Process. Technol., vol. 89, no. 12, pp. 1281-1286, 2008.

W. Huang, K. C. Xie, J. P. Wang, Z. H. Gao, L. H. Yin, and Q. M. Zhu, "Possibility of direct conversion of CH4 and CO2 to high-value products," J. Catal., vol. 201, no. 1, pp. 100-104, 2001.

O. Tursunov, L. Kustov, and Z. Tilyabaev, "Methanol synthesis from the catalytic hydrogenation of CO2 over $\mathrm{CuO}-\mathrm{ZnO}$ supported on aluminum and silicon oxides," J. Taiwan Inst. Chem. Eng., vol. 78, pp. 416-422, 2017.

A. Bansode, B. Tidona, P. R. Von Rohr, and A. Urakawa, "Impact of K and Ba promoters on CO2 hydrogenation over $\mathrm{Cu} / \mathrm{Al} 2 \mathrm{O} 3$ catalysts at high pressure," Catal. Sci. Technol., vol. 3, no. 3, pp. 767-778, 2013.

M. K. Koh, Y. J. Wong, S. P. Chai, and A. R. Mohamed, "Carbon dioxide hydrogenation to methanol over multifunctional catalyst: Effects of reactants adsorption and metal-oxide(s) interfacial area," J. Ind. Eng. Chem., vol. 62, pp. 156-165, 2018.

. Ganesh, "Conversion of carbon dioxide into methanol - A potential liquid fuel: Fundamental challenges and opportunities (a review),” Renew. Sustain. Energy Rev., vol. 31, pp. 221-257, 2014.

P. S. S. Prasad, J. W. Bae, S. Kang, Y. Lee, and K. Jun, "Single-step synthesis of DME from syngas on Cu $\mathrm{ZnO}-\mathrm{Al} 2 \mathrm{O} 3 /$ zeolite bifunctional catalysts: The superiority of ferrierite over the other zeolites," Fuel Process. Technol., vol. 89, no. 12, pp. 1281-1286, 2008.

T. Witoon, J. Chalorngtham, and P. Dumrongbunditkul, "CO2 hydrogenation to methanol over $\mathrm{Cu} / \mathrm{ZrO} 2$ catalysts : Effects of zirconia phases,” Chem. Eng. J., vol. 293, pp. 327-336, 2016.

Y. Zhang et al., "Catalytic performance of spray-dried $\mathrm{Cu} / \mathrm{ZnO} / \mathrm{A} 12 \mathrm{O} 3 / \mathrm{ZrO} 2$ catalysts for slurry methanol synthesis from CO2 hydrogenation,” J. CO2 Util., vol. 15, pp. 72-82, 2016. 
C. Temvuttirojn et al., "Role of Calcination Temperatures of $\mathrm{ZrO} 2$ Support on Methanol Synthesis from $\mathrm{CO} 2$ Hydrogenation at High Reaction Temperatures over $\mathrm{ZnOx} / \mathrm{ZrO} 2$ Catalysts,” Ind. Eng. Chem. Res., vol. 59, no. 13 , pp. 5525-5535, 2020.

S. F. H. Tasfy, N. A. Mohd Zabidi, M. S. Shaharun, and D. Subbarao, "Effect of Mn and Pb promoters on the performance of $\mathrm{Cu} / \mathrm{ZnO}$-catalyst in $\mathrm{CO} 2$ hydrogenation to methanol," Appl. Mech. Mater., vol. 625, pp. 289292,2014

M. K. Koh, M. M. Zain, and A. R. Mohamed, "Exploring transition metal (Cr, Mn, Fe, Co, Ni) promoted coppercatalyst for carbon dioxide hydrogenation to methanol," AIP Conf. Proc., vol. 2124, no. July, 2019.

S. F. H. Tasfy, N. A. M. Zabidi, M. S. Shaharun, and D. Subbarao, "The influence of Mn, Zr and Pb promoters on the performance of $\mathrm{Cu} / \mathrm{ZnO} / \mathrm{SBA}-15$ catalyst for hydrogenation of CO2 to methanol," Defect Diffus. Forum, vol. 365, pp. 178-182, 2015.

F. Li, H. Zhan, N. Zhao, and F. Xiao, "CO2 hydrogenation to methanol over La-Mn-Cu-Zn-O based catalysts derived from perovskite precursors," Int. J. Hydrogen Energy, vol. 42, no. 32, pp. 20649-20657, 2017.

$\mathrm{P}$. Gao et al., "Influence of modifier ( $\mathrm{Mn}, \mathrm{La}, \mathrm{Ce}, \mathrm{Zr}$ and $\mathrm{Y}$ ) on the performance of $\mathrm{Cu} / \mathrm{Zn} / \mathrm{Al}$ catalysts via hydrotalcite-like precursors for CO2 hydrogenation to methanol," Appl. Catal. A Gen., vol. 468, pp. 442452, 2013.

J. Xiao, D. Mao, X. Guo, and J. Yu, "Effect of TiO2, ZrO2, and TiO2 -ZrO2 on the performance of CuO-ZnO catalyst for CO2 hydrogenation to methanol," Appl. Surf. Sci., vol. 338, pp. 146-153, 2015.

N. S. A. Halim, N. A. M. Zabidi, S. F. H. Tasfy, and M. S. Shaharun, "Morphology and performance of Cu/ZnO based catalyst: Comparison between Al2O2 and SiC support," AIP Conf. Proc., vol. 1787, 2016.

S. Faiz, H. Tasfy, N. Asmawati, M. Zabidi, M. S. Shaharun, and D. Subbarao, "Effect of Mn and Pb Promoters

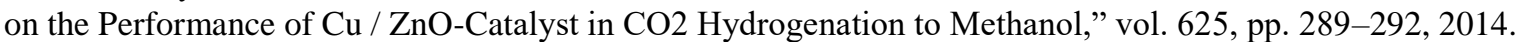

F. E. López-Suárez, A. Bueno-López, and M. J. Illán-Gómez., "Cu/A12O2 catalysts for soot oxidation: Copper loading effect," Appl. Catal. B Environ., vol. 84, no. 3-4, pp. 651-658, 2008.

I. U. Din, M. S. Shaharun, D. Subbarao, A. Naeem, and F. Hussain, "Influence of niobium on carbon nanofibres based $\mathrm{Cu} / \mathrm{ZrO} 2$ catalysts for liquid phase hydrogenation of $\mathrm{CO} 2$ to methanol," Catal. Today, vol. 259, pp. 303-311, 2016.

G. Wu, X. Wang, W. Wei, and Y. Sun, "Fluorine-modified Mg-Al mixed oxides: A solid base with variable basic sites and tunable basicity,” Appl. Catal. A Gen., vol. 377, no. 1-2, pp. 107-113, 2010.

M. K. Koh, Y. J. Wong, S. P. Chai, and A. R. Mohamed, "Carbon dioxide hydrogenation to methanol over multifunctional catalyst: Effects of reactants adsorption and metal-oxide(s) interfacial area," J. Ind. Eng. Chem., vol. 62, pp. 156-165, 2018.

$\mathrm{S}$. Ren et al., "Enhanced catalytic performance of $\mathrm{Zr}$ modified $\mathrm{CuO} / \mathrm{ZnO} / \mathrm{Al} 2 \mathrm{O} 3$ catalyst for methanol and $\mathrm{DME}$ synthesis via CO2 hydrogenation,” J. CO2 Util., vol. 36, no. May 2019, pp. 82-95, 2020.

S. Shaharun, M. S. Shaharun, D. Mohamad, and M. F. Taha, "The effect of $\mathrm{Cu} / \mathrm{Zn}$ molar ratio on CO2 hydrogenation over $\mathrm{Cu} / \mathrm{ZnO} / \mathrm{ZrO} 2 / \mathrm{Al} 2 \mathrm{O} 3$ catalyst," vol. 1621, pp. 3-9, 2014. 